\title{
Process-Event Approach for Operational Risk Estimation
}

\author{
Vasily Karasev \\ Institute of Problems of Mechanical \\ Engineering of Russian Academy of \\ Sciences \\ St. Petersburg, Russian Fereration \\ inorisk@gmail.com
}

\begin{abstract}
Authors propose a new process-event approach for quantitative estimation of operational risk in a bank and calculation the amount of economic capital in dynamics. The proposed approach, according to the Basel II Capital Accord, belongs to the category of "advanced methods". Operational risk is not financial risk and appeared in unfavorable events mainly. A number of business processes are performed in banking activity. Every business process contains a set of routines (operations), which can be interrupted by operational risk events with certain losses. The main idea of the approach is to describe processes as chains of casual events instead of a traditional graphic description as diagrams. Authors introduce new concepts: an elementary process event, a chain of process events, a time diagram of enterprise's event flow, and build logical and probabilistic risk models. Methods and formulas for calculation the current and integrated operational risk in dynamics, the amount of economic capital, upper and lower limits of reservation, are given. The value of integrated operational risk can be used as a rating of the current reliability of the bank. The paper outlines the advantages and disadvantages of proposed process-event approach. Research results can be implemented as analytical tool in risk management technology, "process mining" technology and in bank intelligent management systems.
\end{abstract}

Keywords - process, event, logic, probability, risk, management, event chain, event flow.

\section{INTRODUCTION}

Operational risk is connected with current functioning of bank or company, fraud risk and external events. In most publications the operational risk is considered as one of main risks in commercial bank and there is standard operational risk definition, given in Basel II Capital Accord [1].

In global banking practice, operational risk management is a key and paramount task. Operational risk penetrates all aspects of other possible risks and, more precisely, it is interrelated with all other types of risk (for example, market risk, credit risks and liquidity risks), making them more difficult for estimation. In the absence of operational risk failures, all other types of risk are significantly less important.

In fact, operational risk is not bank phenomenon only.

\author{
Ekaterina Karaseva \\ State University of Aerospace \\ Instrumentation \\ St. Petersburg, Russian Ferderation \\ matatkakate@gmail.com
}

Operational risk is a complex systemic phenomenon in all existing socio-economic systems. This is a non-financial risk and it influences on activity of any economic subject - a commercial enterprise, an investment company, an industrial enterprise, a social institution, executive and legislative authorities, army.

For banks, the Basel II agreement defines a choice of three approaches for operational risk estimation and capital reservation: the base indicator method, the standardized method, and the advanced method [1]. But for other economic subjects there are no standards and regulatory documents, despite the importance and relevance of the problem.

In this paper we present a new approach for assessment, analysis and management of operational risk for any economic subject.

\section{MAIN DEFINITIONS}

Based on the generally accepted definitions of operational risk, we emphasize the eventual nature of this phenomenon - operational risk is identificated primarily in the events: mistakes of employees of the enterprise, failures of information systems, political events, terroristic attacks, natural disasters. Since events have a different nature, there are difficulties in the formalized description and modeling of operational risk. The problem of assessment and management of operational risk is one of the most difficult problems in risk management [2-4].

There are no standard, regulatory documents and clear methods for operational risk management at commercial enterprises, so, we suppose the actual problem to develop a new methodology based on a process management approach [5]. Also, the assessment and management of operational risk by analyzing business processes and identifying weak points in them is described in detail in [6], but in relation to a commercial bank.

In the process approach, whole activity of bank with used resources is considered as a set of processes. Each process consists of a sequence of actions. Often, the output of one process directly forms the input of the next one. The advantage of the process approach is the continuity of management, which is provided at the junction of individual processes within their system, as 
well as with various combinations of processes and their interactions.

The distribution of business process management information systems (BPM), workflow management systems (WFM), ERP II systems and case handling systems provides possibility to record individual events and keep event logs during the operation of the enterprise (bank). These datasets (or protocols) are very useful for analysis and making management decisions and they are applied in other areas, for example, in transport - many cars and public transport are equipped by information system with event log.

There is a task to "extract" processes from the event logs of the information systems in organizations and enterprises. This task is especially relevant in cases where a formal description or model of the system is missing or has low compliance with the actual behavior of the system, that is, in $98 \%$ cases. To solve this problem, Process Mining technologies [7] are being actively developed, which allow to extract a process model from the event $\log$, check its consistency on the statistics of subsequent events, and improve the model if there is a discrepancy between the model and process data.

To construct models of business processes, there are several sets of graphic symbols (notations). At the same time, the description and analysis of business processes in bank based on notations only have some disadvantages:

- high-level processes are described simply and the value of such work is the highest, but the description of detailed processes at a lower level requires a heavy work with a low value. Reduction the level down (almost up to individual employees) leads to excessive complexity of the scheme, loss of visibility and control, while expenses at lower levels are often negligible. That is, 5 - 7 levels of processes is optimal;

- the fragmentation in description does not allow to get a complete picture of the bank as a whole system, to display its functional hierarchy, the structure of resources, to distinguish time stages strictly. Bank model in a process approach consists of a large number of local schemes reflecting various aspects of bank's activity from different levels and viewpoints, but interconnected through an intuitive image of the whole in the developer's mind only [8];

- absence of effective methods for analysis and optimization of business processes;

- the inability to quantitatively calculate the value of operational risk and the amount of reserved economic capital.

In [8], a new subject-event approach to the description of business systems is described. The enterprise (bank), as a system (or integrity, distributed in time), should be described as a stream of events: if we fix an exhaustive set of all events occurring in enterprise, then we get a full description of enterprise as a complete system. The basics of such eventual approach to the description of phenomena and processes were stated in the works of the famous philosophers L. Wittgenstein [9] and B. Russell [10].

The basis of our proposed process-event approach is the concept of separate chains of significant elementary events from the business processes of the bank. To determine the numerical value of the operational risk in the bank, we will use the logical-probabilistic method applied by the author to solve the problem of assessment, analysis and management of operational risk in accordance with the Basel II standard [11, 12].

We introduce several basic definitions.

Process - an orderly interconnected sequence of events and actions (functions, procedures, operations) performed by employees and departments of the organization to obtain the desired final result (goal achievement, problem solving, program implementation, service provision).

Event is the successful completion of action (function, procedure, operation), or successful state (permissible values of process parameters at a certain time period). This event is random. Since any function, procedure or operation may be incomplete during allotted time (due to equipment failure, power failure, personnel errors and other factors), this event may occur or may not occur with a certain probability.

An elementary event is a random event, which is impossible or impractical to split further into events (initiating events in relation to the primary event). An elementary event corresponds to the simplest indivisible action (operation) of the process.

How to select elementary events? This question is not simple and very important. In work [13], for example, a general principle for distinguishing events was formulated: an event is considered as elementary if at least one of three conditions is observed:

1. The event is executed or registered by one of the subjects of the system;

2. The event is executed with one of the objects of the system;

3. The fact of the presence (or absence) of an event is a condition for this event to be executed by another subject or the same subject but with another object.

Thus, the event is determined by specifying the object (s) with which it occurs, and the subject who performed or registered it. The subject can be a specific person, role, team, as well as software, sensors, etc. Events that affect the behavior of the system but are not associated with any of its subjects, should be attributed to the absolute subject. Because any event in the system is determined as events only under the conditions of its connection with a specific subject, the author describes the approach not as event-driven, but as subject-event.

A process event chain is a sequence of random events related to the successful completion of an action (functions, procedures, operations). In our interpretation, the number and sequence of events in the chain corresponds to the number and sequence of actions in the business process.

Thus, a business process can be considered as a sequence of non-random actions, but the result of each action is a random event.

Business processes can be executed both sequentially (when the output of one business process is the input for another), and in parallel.

Set of processes in bank can be defined by set of process event chains, so the state of the bank at time $t$ 
can be described by a set of current unrealized events St from parallel processes, taking into account the logical connections between them.

Events in some processes will have a high probability of occurrence, i.e. be almost reliable (for example, the event "compilation of annual reporting documents"), while in others the probability of their appearance will be significantly lower, for example, in business processes of management of investment projects. This is taken into account when probabilities of events are determined.

An active process is a process, where there is at least one operation, procedure, work, or function is performed at a given time.

Operational risk - the probability of non-appearance of elementary event in the chain. This is a slightly varying value, within the boundaries of a given time interval (before updating statistical data, it is advisable to consider this value as constant).

The operational risk of a bank is the integrated value of the operational risk of the entire bank, i.e. the logical sum of operational risk values at all parallel processes. This value is changed in dynamics during the entire time of bank's functioning.

\section{THE METHOD}

The totality of all the processes $E P_{i}$ of a bank as the events chains forms a non-empty finite set $B, E P_{i} \in B, i$ $=1, \ldots, k$, where $k$ is the total number of distinguished processes in the bank. Some processes from this set are performed in parallel (in time), so in every time $t$ on the cut of the time diagram we have set of events $S_{\text {, }}$, consisting of currently unrealized at the time $t$, events chains $E P_{i}, i=1, \ldots, k$.

Let us assign logical variables $X_{m}, m=1, \ldots, n$ to events from the set $S_{t}$, where $n$ is the number of bank's processes that are active at the time $t$. The logical variable $X_{m}$ can take the value 1 (event occurred) with probability $P(X$ $=1$ ), or the value 0 (event not occured) with probability $Q\left(X_{m}=0\right)=1-P\left(X_{m}=1\right)$. At time $t$, any event $X_{m}$, or several events at once, or all events from the set $\mathrm{S}_{\mathrm{t}}$ may not occur.

The logical function of the integrated operational risk is written in the following form:

$$
X_{O R}=\bar{X}_{1} \vee \bar{X}_{2} \vee \ldots \vee \bar{X}_{n}
$$

Then the total integrated operational risk $P\left(X_{O R}\right)$ can be calculated from the expression (probability function) [14]:

$$
P\left(X_{O R}\right)=1-P\left(X_{1}\right) P\left(X_{2}\right) \ldots P\left(X_{n}\right) .
$$

The value of $P\left(X_{O R}\right)$ is the probability of nonrealization of any event in the set $S_{t}$. Now, if we know the value $P\left(X_{O R}\right)$, we can calculate the size of the reserved economic capital from the expression:

$$
R C=P\left(X_{O R}\right) L,
$$

where $L$ is the average loss due to operational risk events for the previous three years ${ }^{1}$.

During the working day (trading day) the value of $P\left(X_{O R}\right)$ is constantly changing. In this case, it is impractical to calculate this at each time moment.

In the traditional process approach, detailed diagrams of business processes (often in different notations) are compiled and one-time simulation is performed using special software, or diagrams are analyzed "manually". According to the results of simulation and analysis, weak and inefficient connections in the organization of processes are identified and measures are being taken to eliminate deficiencies. After some time, the simulation is performed again, as a rule, this is preceded by a large changes in the bank's activity due to the introduction of new technologies, improvement of the organizational structure, changes in the economic and political situation.

In the process-event approach, we primarily "extract" processes and form event chains. At the same time, we can also use business process diagrams, which were constructed earlier. Then, we cut off the fundamentally impossible sets of $S_{t}$ (a combination of incompatible events) in chains of parallel and sequential business processes. Further, all possible $S_{t}$ sets are generated and the $P\left(X_{O R}\right)$ values are calculated in several most critical $S_{t}$ sets (where $P\left(X_{O R}\right)$ is the largest).

The value of $P\left(X_{O R}\right)$ can be used as a current indicator of the reliability of bank, since this is essentially a convolution of other risks due to the fact that all risks are included in probabilities of elementary events in processes.

By analogy with the method, described in [12], we introduce the concepts of the upper and lower limits of operational risk, respectively, the upper and lower limits of capital reservation. The upper limit $P\left(X_{O R}\right)$ is determined by the maximum value of operational risk obtained on the $S_{t}$ sets, the lower limit is determined by the minimum value $P\left(X_{O R}\right)_{d o w n}$.

The calculation of the upper and lower limits of capital reservations is performed according to the formulas:

$$
\begin{gathered}
R C_{u p}=P\left(X_{O R}\right)_{u p} L, \\
R C_{\text {down }}=P\left(X_{\text {OR }}\right)_{\text {down }} L,
\end{gathered}
$$

The choice of the reservation value is determined by the current economic and political situation, values of main market indices, the experience of the risk manager and the completeness of the information available to him (her).

\section{DISCUSSION}

The process-event approach is further evolution of the traditional process approach to enterprise management. The implementation of event description for processes 1 This period is determined by requirements in Basel II Capital Accord for banks. In fact, the period can be determined by the risk manager, depending on the frequency of fixed cases of operational risk. 
allow us to solve, in practice, the complex task of the quantitative assessment of operational risk which is too difficult to formalize.

At the current stage of development of the new technique, several advantages of the process-event approach have already become apparent:

1. To describe processes of bank's functioning, we need less variables than in the traditional process approach, using notations.

2. Modeling business processes through chains of events allows us to calculate the operational risk value on realization of events at time $t$, identify the most dangerous combinations of events and calculate the amount of reserved economic capital.

3. The process-event approach allows us to calculate the operational risk not only as a probability of unfavourable event among set of internal events of processes, but also taking into account external events (changes in legislation, natural disaster, fraud, armed robbery, terroristic acts etc.). We can perform this by adding corresponding logical variables to formula (1). However, it should be assumed that when we determine probabilities $P\left(X_{i, m}\right), m=1, \ldots, n$ according to the event protocol (statistical data), the influence of external factors is already taken into account in the values of these probabilities.

4. The process-event approach uses simple and transparent formulas to calculate the operational risk and the amount of economic capital, reserved to cover possible losses. But this advantage is takes place in application the process-event approach to solution the problem of quantitative assessment of operational risk only. In other tasks (for example, optimization of organizational structure and bank management procedures) this advantage is not obvious.

The process-event approach also has disadvantages:

1. The absence of clear recommendations about the selection of events. We recommend to select elementary events that have a fundamental impact on the logics of the process and can be observed and recorded.

2. Difficulties may arise in determination probabilities of events $P\left(X_{i, m}\right)$. In the absence of statistics, expert methods have to be applied, which reduce the reliability of results.

3. The process-event approach requires a certain level of knowledge and competence of the manager (specialist). The manager needs some preliminary practical experience in the decomposition of processes and the identification of elementary events.

\section{CONCLUSION}

The idea of event-process approach is new, therefore, there are many questions that require more detailed study.

Existing operational risk management technologies often overlook the main fact: operational risk is nonfinancial risk and realize in separate events.

Authors took this feature into account and proposed a process-event approach for quantitative assessment of operational risk, introduced basic definitions and provided logical and probabilistic models of operational risk in banks.

\section{REFERENCES}

[1] International Convergence of Capital Measurement and Capital Standards: A Revised Framework, Bank for International Settlements Press \& Communications CH-4002 Basel, Switzerland, 2004, 251 p. [Online]. Available: https://www.bis. $\mathrm{org} /$ publ/bcbs107.pdf [Accessed: Feb. 20, 2019].

[2] Kaspereit T., Lopatta K., Pakhchanyan S., Prokop J. Systemic operational risk / Journal of Risk Finance. - Vol. 18, Issue 3. 2017. - pp. 252-262.

[3] McKim V.L. Operational risk assessment / Journal of Business Continuity \& Emergency Planning. - Vol. 10, Issue 4. - Summer, 2017. - pp. 339-352.

[4] Panjer H.H. Operational Risk: Modeling Analytics. - Wiley, 2006. -448 p.

[5] Reengineering the Corporation: A Manifesto for Business Revolution, Michael Hammer and James Champy, Nicholas Brealey Publishing. London, 1993 (Harper Collins in U.S.A), 223 p.

[6] Сазыкин Б.В. Управление операционным риском в коммерческом банке. М.: Вершина, 2008. - 272 с.

[7] Wil M.P. van der Aalst. Process Mining: Discovery, Conformance and Enhancement of Business Processes. - Springer-Verlag Berlin Heidelberg, 2011. - 352 p.

[8] Болдачев А., Шумаков А. О принципиально новом, субъектнособытийном подходе к моделированию бизнес-систем. [Online]. Available: http://www.rsci.ru/rt/researches/236426.php, [Accessed: Jul. 15, 2018]

[9] Wittgenstein L. Tractatus Logico-Philosophicus. New York: Harcourt, Brace, 1922, 75 p.

[10] Russel B. The Philosophy of Logical Atomism. London and New York, Routledge Classics, 2010, 162 p. [Online]. Available: https://sites.ualberta.ca/ francisp/NewPhil448/ RussellPhilLogicalAtomismPears.pdf [Accessed: Feb. 25, 2019].

[11] Author, 2012.

[12] Author, 2016

[13] Болдачев А. Субъектно-событийный подход к моделированию сложных систем. [Online]. Available: https:/habrahabr.ru/ post/256509/, [Accessed: Jul. 15, 2018].

[14] Solozhentsev E.D. The Management of Socioeconomic Safety / Solozhentsev E.D. -Cambridge Scholars Publishing, 2017. - 255 p. 